Recebido: $31 / 08 / 2017$

Aprovado: 29/11/2017

\title{
Por uma teoria da História pela História: Sobre o fetiche do distanciamento ${ }^{1}$
}

João Francisco Schramm*

Resumo: O surgimento e abandono de modas e de modelos teóricos alienígenas à História são tratados muitas vezes pela historiografia como algo trivial, havendo na maior parte das pesquisas apenas exposição dos debates da época, ao expor as correntes teóricas anteriores e as que mais tarde vieram se firmar no novo cenário epistemológico. No entanto, o presente artigo expõe que tais modelos teóricos, tão logo configurados como a moda de uma época, revelam problemas maiores, ainda não assumidos pela História, que demonstram o estado de experimentalismo, sujeição e dependência a que a disciplina esteve sujeita durante o séc. $X X$. Ao fazer se submeter às modas teóricas e às repentinas mudanças de outras disciplinas, a História durante o séc. XX (especialmente na França e em consequência no Brasil), acabou por assumir questões epistemológicas que estão na raiz do próprio surgimento das ciências sociais, quando esta defendia a criação de um método semelhante ao das ciências da natureza, a que pudesse desvelar leis gerais que regem o comportamento humano. Sobre essa questão em particular, este artigo oferece uma crítica à ideia corrente de "distanciamento", que poderia trazer às ciências sociais modelos teóricos e sistemas de interpretações que tornariam supérfluos a singularidade do conhecimento histórico ou mesmo a empiria. Portanto, o artigo discute o lugar não somente da História, mas das ciências humanas, quanto a seu objeto específico de estudo em relação às ciências naturais, ao destacar diferenças relevantes entre objetos culturais e objetos naturais.

Palavras-chave: Historiografia; Teoria; Distanciamento.

Abstract: The emergence and abandonment of fashions and alien theoretical models to History are often treated by historiography as trivial, with most of the research being only an exposition of the debates of the time, by exposing the previous theoretical currents and those that later came to be signed in the new epistemological scenario. However, this article exposes that such theoretical models, as soon as configured as the fashion of an era, reveal greater problems, not yet assumed by History, that demonstrate the state of experimentalism, subjection and dependence to which the discipline was subjected during

\footnotetext{
${ }^{1}$ O presente artigo é o segundo da série Por uma teoria da História pela História, que tem como tema a influência das ciências sociais na História, ao expor um debate historiográfico e os novos desafios atuais a disciplina, na emergência de teorias e perspectivas originárias de seu próprio seio. Acesse o primeiro artigo em: http://www.desafioonline.ufms.br/ojs/index.php/moncx/article/view/156

* Doutorando do Programa de Pós-Graduação em História da Universidade de Brasília.
} 
the century XX. When submitting to the theoretical fashions and the sudden changes of other disciplines, History during the century. XX (especially in France and consequently in Brazil), ended up assuming epistemological questions that are at the root of the very emergence of the social sciences, when it defended the creation of a method like the one on natural sciences, which could reveal general laws that governing human behavior. On this particular issue, this article offers a critique of the current idea of "distancing", which could bring to the social sciences theoretical models and systems of interpretations that would render superfluous the uniqueness of historical knowledge or even empiricism. Therefore, the article discusses the place not only of History, but of the human sciences, as to its specific object of study in relation to the natural sciences, by highlighting relevant differences between cultural objects and natural objects.

Keywords: Historiography; Theory; Distancing. 
A História, logo após sua criação como disciplina acadêmica, permaneceu em constante debate com as ciências sociais. Durante boa parte do século XX, ao menos na França, a História buscou certa interdisciplinaridade em empréstimos dos grandes modelos teóricos das ciências sociais, ao acompanhar suas modas e mudanças correntes. O surgimento e queda das modas e tendências teóricas oriundas da Sociologia e Antropologia revelam questões que percorrem a História em estabelecer seus próprios limites e sua autenticidade, já que submetendo-se a tais tendências, a disciplina passou a assumir também a desvalorização de certas viradas teóricas que hoje já não mais "convencem" - as modas teóricas e seus repentinos abandonos indicam um estado de experimentalismo que a disciplina não protagonizava como vanguarda, mas sim, se adaptava pelo embalo de uma novidade, e quando o modelo em seu meio originário perdia sua força, a disciplina também demorava por abandoná-lo.

Para melhor debater essa questão, que discorre sobre a influência das ciências sociais na História, o objetivo desse artigo é discutir o problema do distanciamento sociológico e antropológico, que tem como meta a construção de sistemas de interpretações teóricos macrossociais para além dos fatos/acontecimentos, para além da empiria, ou mesmo das pesquisas sociais "conteudistas".

Explícito em tal distanciamento está a ideia de que os cientistas humanos conseguiram ou conseguirão elaborar e organizar um conhecimento teórico que lance luz sobre a investigação social de forma que possa "sobrevoar" rapidamente extensas áreas que tradicionalmente somente seriam transpostas pelo vagaroso trabalho empírico, ou seja, tal distanciamento possibilitaria a construção de um sistema teórico que tornaria supérflua, ou quase desnecessária, a pesquisa em campo, em que esta também seria vista como incapaz de elevar-se ao ponto de, sozinha, perceber tal elucidação teórica.

A crença no distanciamento científico e sua possibilidade de reconstrução da vida social, por meio de categorias e sistemas para além dos acontecimentos, é parte constituinte do início do processo de fundação próprio às ciências sociais, por consequência, esses processos foram influentes nos modelos epistemológicos da História do século XX, notadamente na França e, por conseguinte, no Brasil também.

Nesse sentido, ao abordar o estado de arte acerca das correntes teóricas pelo qual a História esteve sujeita desde o período de sua fundação como disciplina acadêmica no séc. XIX até os dias de hoje, centralizada no debate dessa disciplina com as ciências sociais, esse artigo esboçará uma discussão mais ampla centralizada no distanciamento como método intrínseco às

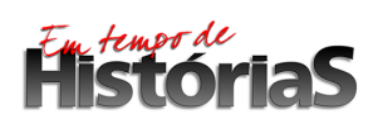

(PPGHIS/UnB) №. 31, Brasília, Ago - Dez 2017 ISSN 2316-1191 
ciências sociais e como que essa ideia de se distanciar nos remete a questões ainda não resolvidas pela História. Ou seja, carece ao debate historiográfico uma crítica profunda acerca da influência das ciências sociais sobre a disciplina, já que sem ela poderíamos repetir o constante ciclo de apropriações de sistemas teóricos alienígenas à História, experimentando, novamente, o surgimento e abandono de modas que não mais fazem sentido à comunidade científica.

\section{O surgimento das ciências sociais e sua influência sobre a História}

Ao se estabelecer como disciplina autônoma e universitária a escola metódica do século XIX se afirmou num amplo debate com o que até então era conhecido como "fillosofia" da história. Essa concepção histórica, que trazia em si a ideia de uma História única, embalada pelo progressismo moderno, foi duramente questionada como modelo positivista de análise que concebia a História um movimento linear de desenvolvimento, na existência de uma linha central (que variava, dependendo da "filosofia" defendida), a que todas as outras demais histórias singulares estariam ligadas e expressariam seu sentido.

Tais projetos, combatidos pela escola alemã como "filosofia da história", assumiam de forma clara os grandes ideais que fundamentam a modernidade, especialmente a ideia do progresso, ao encampar projetos políticos futuristas que não mais buscavam inspiração no passado, mas sim no futuro, como o republicanismo, o liberalismo, o comunismo, ou mesmo no século XX, o fascismo, a ponto de afirmarem sentenças históricas que não mais se apoiavam em experiências passadas, mas sim na própria expectativa de sua execução. ${ }^{2}$

Podemos ver na teoria da História de Karl Marx um exemplo interessante do uso filosófico do conhecimento histórico ao qual os historiadores metódicos se opuserem: a história seria guiada por um fio condutor presente na luta de classes entre forças produtivas e relações de produção, ou seja, as transformações e mudanças histórias seriam fruto de forças dialéticas sempre presentes e em luta.

Ainda segunda a teoria marxista, o futuro aguardava um retorno inexorável a um comunismo mitológico, pré-histórico, antes da agricultura e decorrente divisão do trabalho,

\footnotetext{
${ }^{2}$ Koselleck (2006), aponta como que na modernidade, a distância entre a experiência e a expectativa se tornava cada vez maiores, em que o passado já não servia como aprendizado e as lutas políticas, embaladas pela queda da monarquia francesa, buscavam suas orientações num futuro que estava por se construir.
}

\section{Filistorias}


consequência da acumulação. No entanto, o comunismo do futuro, que marcaria o fim da História, tomaria a característica de uma experiência humana industrial. Nessa teoria, o passado mitológico comunista pré-histórico, antes da acumulação e divisão de classes, era um marco limite inicial da teoria da História (do motor da história), e o futuro de um comunismo industrial, que marcaria o fim da acumulação e da sociedade de classes é o seu marco final, o próprio fim da História.

Como parte de um amplo movimento europeu que passamos a abordar como modernidade, em que a experiência europeia é o espelho e a medida de quaisquer outras experiências culturais e civilizatórias, Marx, em sua teoria, negava o passado e a tradição, mesmo das culturas europeias, face ao otimismo da civilização ocidental quanto ao futuro de toda uma humanidade, ao estabelecer as regras que permeiam o próprio devir histórico, aplicável a qualquer experiência humana. ${ }^{3}$

Com a dissolução da URSS em 1991, ideólogos liberais como Francis Fukuyama, decretaram também, a seu modo e de forma triunfal, o fim da História, já que o liberalismo acabou vitorioso ante o fascismo em 1945 e agora contra o socialismo, em 1991, não havendo mais espaço para concorrência real e geopolítica para o projeto liberal liderado pelos EUA, no advento de um poder em escala mundial.

Sob tal perspectiva unipolar, em que países liberais viveriam em estado de paz permanente, pois ao compartilhar um sistema econômico e político semelhante, jamais entrariam em guerra, o mundo burguês e democrático passou a ser visto e defendido como a melhor opção para os povos, que, sob os impulsos da globalização dos mercados, a economia e a tecnocracia, por fim, substituiriam a política.

Nessa concepção histórica, o mundo burguês liberal foi aquele que, além de ser o vitorioso, foi o que alcançou o ápice da evolução na organização social humana. O sucesso da obra de Fukuyama em que ele defende sua tese, O Fim da História e o Último Homem, demonstra que esquemas explicativos históricos lineares, de sentido único e ideológicos não foram esgotados e ainda acompanham diferentes abordagens cientificas.

Foi contra essas teorias que tematizam a História segundo um sentido ideal que a escola alemã se consagrou, já no século XIX, ao estabelecer a profissionalização acadêmica da

\footnotetext{
${ }^{3}$ Podemos até utilizar a teoria marxista para compreendermos os conflitos de classe, políticos e sociais, após a Revolução Francesa, especialmente nas sociedades industriais, burguesas e proletárias, mas aplicá-la para compreendermos sociedades do Antigo Regime e mesmo sociedades e civilizações de outras matrizes culturais já não faz sentido.
} 
disciplina. O intuito era estabelecer as bases de uma ciência histórica que poderia conter a objetividade de um método baseado majoritariamente na crítica documental das fontes, no intuito de criar histórias singulares, na crença de que todo acontecimento é único, numa metodologia amplamente embasada na empiria. Isso tudo contribuiu para a afirmação de uma disciplina acadêmica formalmente construída segundo o método hermenêutico, com o apoio de disciplinas auxiliares como, por exemplo, a filologia, a linguística, paleologia, a geografia etc.

Foi durante a últimas décadas do século XIX, num momento em que a escola metódica conquistava seus méritos científicos e institucionais, que a Sociologia inicialmente tentou se estabelecer como um ramo das ciências humanas que pudesse se colocar como uma ciência positiva, com a legitimidade de uma ciência natural, não apenas em seu método, mas também em seu objeto. Para isso, ela teria que se afirmar como um ramo científico superior à História, algo como que inevitável em sua busca por legitimidade e espaço institucional, e também pelo que ela prometia como resultados. No entanto, antes mesmo de buscar se afirmar como uma nova ciência, a Sociologia de Emile Durkheim teve que concorrer com outras correntes sociológicas que tentavam emergir no final do século XIX, como a corrente defendida por Gabriel Tarde, jurista francês.

Para Tarde, os méritos da Sociologia necessariamente estariam associados à subjetividade do cientista, devida a sua ideia de que o progresso da ciência depende da originalidade de indivíduos em situações de meditações solitárias. Durkheim afirmava o contrário, defendendo processos em que a divisão do trabalho, cada vez mais acentuada e coletiva, traria especializações cada vez maiores e isso refletiria nas carreiras acadêmicas e que delas sairiam os cientistas aptos para analisar a sociedade.

Ao enfatizar o conhecimento sociológico sendo produzido por estruturas acadêmicas cada vez mais especializadas e interdependentes, Durkheim aproximava seu intento do que é comum às ciências exatas e naturais, que, na elaboração de seu conhecimento e tecnologias, estão inevitavelmente dependentes de financiamentos acadêmicos, governamentais ou de outras fontes, em laboratórios cada vez mais especializados e grupos de pesquisa numerosos.

Para Durkheim, o modelo da especialização e interdependência seria comum tanto às ciências da natureza quando às ciências sociais, o que faria distinguir a Filosofia ou Linguística da Sociologia, pois esta última disciplina estaria ligada a grandes projetos universitários em departamentos especializados e em pesquisas coletivas. Do debate entre esses dois autores, a vitória foi legada ao modelo de Emile Durkheim. A sua influência, que teve início no campo 
universitário francês do final do século XIX, é fundamental para o programa das ciências sociais até hoje.

Segundo March Bloch, no momento de maior influência da sociologia durkheimiana houve intensa crítica aos historiadores metódicos, tanto por sociólogos quanto por historiadores. A disciplina histórica foi relegada ao relato de acontecimentos, ao fortuito e somente a Sociologia faria o papel de racionalizar as estruturas profundas das sociedades. Ficou claro no debate do jovem sociólogo Simiand contra Seignobos, coautor do famoso livro Introdução aos Estudos Históricos, que a nascente sociologia francesa almejava elaborar uma ciência humana segundo a metodologia de uma ciência natural e assim estabelecer leis que regem o comportamento de sociedades, como forma de desenvolver e aprimorar o projeto de Auguste Comte. ${ }^{4}$

A "coisificação do social" caracteriza bem esse momento histórico em que as ciências da natureza deslumbravam os cientistas sociais, que em seus esforços buscavam um grau de legitimidade científico semelhante. Nesse intento, era coerente tentar descobrir hipotéticas leis que regem o comportamento humano, ou melhor, das sociedades, leis que atuam coercivamente sobre indivíduos, ignoradas pelo senso comum. A delimitação de um novo objeto, o "fato social", veio como uma necessidade de se abstrair uma realidade que até então todas as ciências humanas não haviam conseguido, já que trabalhavam sempre com objetos culturais, portanto, originários e sustentados pela subjetividade individual. Logo, o "fato social" foi uma tentativa de se criar um contraponto ao fato psicológico individual, na necessidade de separar a subjetividade do indivíduo à objetividade do fato - e é nesse sentido que o "fato social" se transforma em objeto, assim como se tem em mira um objeto das ciências da natureza, criandose assim um "objeto natural", a ser analisado agora por uma ciência humana. A Sociologia durkheimiana seria a primeira ciência humana a lidar com objetos naturais.

Por conseguinte, a História de inspiração metódica, essencialmente idiográfica e com uma clássica forma narrativa de expressão, perderia seu crédito como ciência por tratar de questões singulares, eventuais, ao passo que a Sociologia traria as novidades que faltavam às ciências do espírito, no caso, as leis do comportamento humano que moldam as sociedades, ao explicar os fenômenos da vida humana assim como a Física explica os fenômenos físicos.

\footnotetext{
${ }^{4}$ Para mais informações sobre este debate ver, Silva (2014) e Delacroix, Dosse e Garcia (2012).

${ }^{5}$ DOSSE, François. A História. Bauru, São Paulo, EDUSC, 2003. 
O espírito positivista propagado por Auguste Comte, que numa primeira tentativa nomeia a nascente disciplina sociológica de "Física Social", refletia-se claramente no projeto durkheimiano, especialmente quando este delimitava o novo objeto de sua disciplina, o fato social, assim como quando ele e seus colegas, no debate com os historiadores de sua época, argumentava que a História só poderia ser uma ciência se ela se elevasse acima do individual e da narrativa casuística, e caso assim procedesse, se tornaria apenas um ramo da Sociologia.

No entanto, os mesmos historiadores que criticaram os metódicos e a escola alemã, afirmando estes serem "positivistas", por enfatizarem a objetividade da pesquisa histórica principalmente na crítica das fontes e na singularidade do conhecimento histórico, pouco perceberam que a sociologia de Durkheim era muito mais próxima do positivismo de Auguste Comte do que a escola metódica: a própria crença de forças ocultas ao indivíduo que movem a sociedade e que se observadas com "distanciamento" podem ser estabelecidas em leis gerais, noção que contempla parte do projeto durkheimiano, ou mesmo a noção de um "fato social" tangível e objetivo, demonstram semelhanças teóricas com o projeto de Comte, o principal expoente e fundador do positivismo.

Logo, é sobre este debate que os historiadores franceses reunidos em torno da revista dos Anais de História Econômica e Social fundaram uma corrente histórica que carregava abertamente grande influência das ciências sociais, especialmente da Sociologia. O acompanhamento de tais experiências epistemológicas em suas gerações faz parte do currículo básico na formação dos historiadores brasileiros, devido à grande influência que a corrente dos Anais teve não somente na França, mas também no Brasil e outros países.

A intenção dos Anais era de quebrar o relato histórico, demasiadamente narrativo, numa crítica à "história batalhas", demasiadamente política, e à "história dos grandes", demasiadamente centrada em figuras proeminentes, prevalecendo uma nova epistemologia renovada pela crítica ao "acontecimento" e seu relato, uma crítica aberta à forma narrativa e à escola metódica, em prol de uma alegada multidisciplinaridade, especialmente voltada à Sociologia e sua atenção ao "social" e ao "econômico", multidisciplinaridade esta, diga-se de passagem, de mão única, ou seja, apenas os historiadores ligados ao círculo dos Anais tentavam renovar suas pesquisas abraçando outros campos, não havendo reciprocidade em relação as demais disciplinas.

Tal crítica foi encampada pelas primeiras gerações dos Anais em favor de um estudo de forças macrossociais, ao se utilizarem também de uma concepção marxista de que eventos 
políticos são conjunturas de uma "superestrutura", joguetes de formas estruturais/econômicas maiores, nesse caso, o eventual, assim como o fato, o acontecimento ou mesmo a narrativa, perderiam seu valor científico, num momento em que era comum acreditar numa ruptura epistemológica que prometia amplos resultados capazes de lançar luz a vastas regiões e temporalidades.

As concepções teóricas oriundas das ciências sociais, que transportadas agora para a História admitiam uma operacionalização prévia das fontes, concepções essas que almejavam "uma inteligibilidade global do social", 6 acabaram por influenciar as primeiras gerações dos Anais. Sobre esses novos projetos, Jacques Revel, em retrospectiva, afirma que tais primeiras gerações propunham um projeto unificador das ciências sociais, fortemente influenciados pelos marxismo e estruturalismo, a que o autor denomina de funcionalismo. Logo, os projetos de "fílosofias da História", combatidos pelos metódicos acabaram por voltar à tona, mas agora travestidos com uma cientificidade oriunda especialmente da Sociologia e da Antropologia.

É nesse sentido que Ricceur afirma que a desconfiança pela história narrativa, desconfiança essa reerguida pela corrente francesa dos Anais, pois foi construída inicialmente pela sociologia francesa, "constitui assim o avesso polêmico de uma defesa de uma história do fenômeno humano total, com, no entanto, uma forte ênfase em suas condições econômicas e sociais". Ricceur afirma ainda, citando Braudel, que "a ciência social tem horror ao acontecimento". 7 Essa repulsa do "acontecimento" pelas ciências sociais, acabou por ser enaltecida pelo círculo dos Anais, que tomaram de forma parcial o partido dos sociólogos no debate deste com os historiadores da escola metódica, sem admitir totalmente o estatuto epistemológico das ciências sociais, mas estando aberto às suas inovações. ${ }^{8}$

Nessa nova abordagem, o acontecimento e sua forma narrativa foi substituído por modelos criados pela operacionalização de fontes massivas e de procedimentos quantitativos, que de certa maneira, possibilitavam a abstração de uma "história total", ou seja, os historiadores do círculo dos Anais não mais buscavam o singular como seus antigos mestres, mas aquilo que se repete, a longa duração, as estruturas imperceptíveis ordinariamente, em que os acontecimentos são apenas sua realidade superficial - essa nova epistemologia se

\footnotetext{
${ }^{6}$ REVEL, Jacques. História e historiografia. Curitiba: Ed. UFPR, 2010. p.79.

${ }^{7}$ RICCEUR, Paul. A memória, a história, o esquecimento. Tradução de Alain François et al. Campinas, SP: Ed. Unicamp, 2007. Publicando originalmente em 2000. p.252.

${ }^{8}$ Max Weber tomava partido contrário a essa posição, ao defender a singularidade da História como ciência, ele mesmo publicando pesquisas em história comparada sobre o oriente, a antiguidade e o ocidente.
} 
fundamentou nos estudos seriais e isso a qualificou ideologicamente mais científica e objetiva, mais próxima das forças que coagem acontecimentos e indivíduos. Nesse sentido, a história serial e seu projeto totalizante, que enfatiza dinâmicas sociais e econômicas, viria a substituir a história política singular, que compunha o formato narrativo tradicional, mas não único, da disciplina no séc. XIX.

Ainda assim, os historiadores do círculo dos Anais encamparam uma briga contra seus mestres metódicos já "no segundo tempo", somente após os debates entre sociólogos e a escola alemã, e esse movimento inicial, que primeiramente assumiu o papel secundário na disputa, pois a crítica dos Anais já não era uma crítica original, continuou num mesmo formato hierárquico, por assim dizer, durante boa parte do séc. XX.

Sob tal influencia, o protagonismo das novidades teóricas viriam sempre das ciências sociais e a História acabava por se influenciar de forma reativa, numa atitude de sujeição e dependência epistemológica, pois já que a disciplina aceitou o diálogo com as ciências sociais e tomou seu partido na disputa contra a escola metódica e consequentemente, contra si mesma, ela teria que necessariamente responder às suas inovações, acatando, mesmo que inconscientemente, e de forma parcial, a máxima de Durkheim, em que a História (se cumprisse a exigência de elevar-se acima do "individual") se transformaria, apenas, num ramo da Sociologia. Portanto, tais ações levaram a disciplina a se sujeitar num círculo vicioso de novidades alienígenas.

A História encontrou seus inimigos internos e, como não era estritamente uma ciência social, mas seguia essa em seus passos teóricos e modas, acabou por ficar num limbo, praticando o experimentalismo da combinação narrativa temporal sob a influência de teorias e modelos sociológicos e antropológicos. Num estatuto de trepidez interdisciplinar, a História já não sabia ao certo qual era seu lugar certo nas humanidades, pois estava marcada numa situação ambígua, de sujeição metodológica, que muitas vezes encampava disputas institucionais e de financiamento, a que a disciplina reagia ao se ver ameaçada por certas inovações de disciplinas vizinhas.

Sobre essa situação, Roger Chartier (1990), demonstra a forma reativa a que a disciplina na França da década de 1970 se submeteu, época em que ainda estava atrelada à uma interpretação macrossocial das sociedades. Nesse momento, a disciplina se viu ameaçada institucionalmente quando a Sociologia já não mais se interessava pelas hierarquias e posições, mas pelas relações e representações, por exemplo. Daí a emergência de novos objetos de 
estudos históricos (não mais alinhados ao estudo de "mentalidades", ou abordagens seriais e quantitativas), como sistemas de parentesco, crenças, comportamentos religiosos, atitudes perante a morte, etc.

Não é intuito deste artigo continuar o debate historiográfico que ocorreu durante as várias crises posteriores da História, como aponta Revel (2009), que renovaram a disciplina, de forma ainda bastante influenciável pelas próprias mudanças oriundas das ciências sociais, mas agora abandonando modelos de análise de "sociedades sem atores", comuns aos anos de 1950 e 1960, inaugurando, já na década de 1980 novos olhares e perspectivas teóricas que moldaram o atual estado de arte de disciplina, que busca elaborar questões teóricas oriundas de seu próprio meio, abrindo mão, quase por completo, de esquemas teóricos que operacionalizam previamente as fontes, ou seja, que se sobrepunham a estas antes mesmo de sua consulta. ${ }^{9}$

A maior liberdade metodológica que os historiadores exercem hoje é fruto de um amplo percurso historiográfico que ainda se faz presente, mas que não será aprofundado por este artigo, já que seu tema central se relaciona a uma crítica ao "distanciamento". O intuito de acompanhar o leitor sobre as influências das ciências sociais sobre a História é preâmbulo geral para tal crítica, já que seu foco não é fazer um apanhado geral da historiografia desde da profissionalização da disciplina no século XIX até hoje, mas sim, demonstrar as consequências de tal influência.

\section{Sobre o fetiche do distanciamento}

Ao elaborar seu objeto por meio de uma abstração que confere certa legitimidade objetiva a novos entes, como o "fato social", ou as estruturas macrossociais, ou os quadros estruturalistas, que muitas vezes são compostos por massivas fontes primárias em modelos teóricos que operacionalizam essas fontes previamente, as ciências sociais fundamentaram a realidade empírica de seu objeto na criação de novos entes culturais e conceitos com o intuito, pelo menos inicial, de criar um objeto de pesquisa semelhante aos objetos das ciências naturais.

Para isso ser possível, ela se baseou na crença do distanciar-se, em que por meio deste ato, do "distanciamento científico", o cientista poderia estabelecer estruturas que existem, mas que não são percebidas ordinariamente. Essa vontade de distanciar-se tem como intuito final

\footnotetext{
${ }^{9}$ Para um aprofundamento de tal debate, ver Schramm (2014). 
elaborar leis que regem o comportamento humano, que possam ser usadas como ferramenta de análise da realidade social, leis essas que acabam por operacionalizar a fonte segundo uma lógica própria, antes mesmo de sua análise.

Tal pretensão de distanciar-se nos leva inevitavelmente para a quimera entre as ciências naturais e as ciências humanas, já que é assumido pelos fundadores das ciências sociais, notavelmente da Sociologia, que essa nova ciência tinha pretensões de ser fundamentada em métodos das ciências da natureza. Para tanto, ela teria que inventar ou descobrir um objeto que também que fosse "natural", ou seja, um objeto que não fosse um ente cultural, que pudesse ter uma existência própria, que não dependesse da subjetividade dos indivíduos, um objeto que, enfim, pudesse ser observado à distância, afim de que seus mecanismo, repetições e comportamentos fossem devassados, assim como são devassados os fenômenos da natureza.

Nos primeiros debates entre sociólogos e historiadores, as estruturas ou realidades totais (sociais, econômicas etc.), se contrapunham aos acontecimentos e a singularidade. Essas novas realidades remetiam a ideias de repetição e manutenção, de estruturas e realidades que poderiam ser aplicadas a ambientes culturais muitas vezes distintos, e que também estão além dos “acontecimentos", por estarem na base socioeconômica ou cultural de uma sociedade.

Mas como passou despercebido por essa primeira geração de sociólogos o problema essencial, e de base filosófica, de tentar estabelecer objetos supostamente não humanos para uma ciência humana? A minha tese é a seguinte: para uma nascente ciência social tentar conquistar a mesma legitimidade cientifica de uma ciência da natureza, na criação de leis irrefutáveis, ela teria necessariamente de trabalhar com objetos também "naturais" e que para tanto, foi estabelecido um ato de "distanciar-se" do mundo social, tanto para estabelecer suas leis, como para delimitar tal objeto. No entanto, o distanciamento provou ser mais um poderoso fetiche do que uma ferramenta teórica razoável.

O repentino abandono desses modelos e práticas de pesquisa, tendo visto as inúmeras modas e correntes teóricas que cientistas sociais e historiadores adotaram durante boa parte do século XX e que hoje não fazem mais sentido, é sintoma de que o "distanciamento", na elaboração de leis e teorias da análise do comportamento humano, não se sustenta como uma teoria de conhecimento razoável.

No entanto, por mais que tais abandonos teóricos sejam admitidos por aqueles que se debruçam em investigações sociais, o debate historiográfico que aponta tais modas e suas metodologias inflexíveis, na maior parte das vezes apenas remonta os embates de uma época,

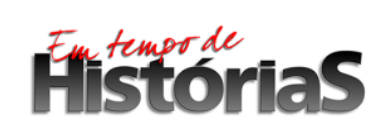

(PPGHIS/UnB) №. 31, Brasília, Ago - Dez 2017 ISSN 2316-1191 
que envolvem questões institucionais e de financiamento etc., ao descrever certas novidades e abordagens que não convencem mais hoje, sem se ater numa crítica profunda acerca do erro cometido, se é que ele é admitido.

O problema de acreditarmos que modas e repentinos abandonos são práticas comuns na investigação social é correr risco de não nos anteciparmos em olhar nosso próprio tempo com a crítica devida, já que ele também pode carregar em si um modelo teórico alienígena, que também poderá ser abandonado, ou então, que tal ou qual modelo teórico "do momento" seja apenas usado como uma forma de legitimidade perante a comunidade científica. Para esta situação em particular, o trabalho de Koselleck, atualmente revisitado no Brasil, e as categorias de "espaço de experiência" e "horizonte de expectativa", servem como exemplo de uso indevido de questões teóricas, apenas com fito legitimidade, que ocorrem sem a devida busca de estratos de tempos históricos particulares à pesquisa, que é a contribuição de fundo a que tais categorias se dirigem, podendo ser aplicadas a distintas pesquisas, que se ocupam, sobremaneira, com a própria possibilidade em se produzir um conhecimento histórico, na elaboração de diferentes estratos de tempo interconexos (e de diferentes durações), que podem ser ressaltados e conceituados ao fazerem parte do tempo e espaço particular a que o historiador se dedica em sua pesquisa.

Ou seja, a teoria é evocada apenas como máscara, o que demonstra certa inexperiência do pesquisador, já que não há aprofundamento daquilo que a teoria tem para esclarecer e orientar, desconectada do restante do texto, semelhante ao que era bastante comum em dissertações e teses de gerações passadas, quando dedicava-se um capítulo inicial a "premissas teóricas", em que o pesquisador basicamente provava o entendimento das principais correntes em voga de seu tempo, ou mesmo defendia aquelas ligadas à sua ideologia, mas que, como no caso anterior, na maior parte das vezes não se relacionavam com os demais capítulos do texto. Tais situações demonstram o poder legitimador que as correntes teóricas tiveram, e ainda tem, nas humanidades. Nas pesquisas históricas isso é mais grave ainda, já que o desarranjo entre teoria e empiria é algo difícil de se camuflar, tendo em vista seu caráter "conteudista", de predileção a fontes primárias, em comparação com a Sociologia, por exemplo, nitidamente de tendência nomotética.

Retornando à discussão sobre o distanciamento, se toda ciência humana é feita de abstrações culturais e mentais, ou seja, estão baseadas em um léxico e em um ato, que é o pensar, logicamente o seu objeto é abstrato, ou seja, ele é criado e sustentado pela mente humana 
que o pensa. Nesse sentido, ele só existe como um objeto cultural, ou seja, a metodologia das humanidades se dá sobre a análise e o pensamento de um ente cultural, fruto também de um pensamento. Por consequência, esse ente cultural só existe por que é sustentado por uma mente que vive e que o dá suporte enquanto pensamento vivo. Em outras palavras, a cultura humana, além de só fazer sentido para seres humanos, também depende de seres humanos vivos e pensantes para poder existir. Isso parecer ser algo bastante óbvio e razoável.

Nesse sentido, o objeto das humanidades depende do pensamento humano, de pessoas vivas sustentando-os em pensamentos. Essa é sua forma de existência. Logicamente, é a mesma mente também que analisa esse objeto sustentado por ela. Ou seja, sobre o objeto cultural, o objeto das humanidades, a mente humana faz um duplo processo: ao mesmo tempo que cria, sustenta e faz existir o objeto, também tenta investigá-lo, analisá-lo, compará-lo com outros e reordená-lo cientificamente. Esse duplo jogo mental de pensar algo (a análise) que depende do pensamento para existir (o objeto), sugere a impossibilidade de se "distanciar" de um objeto cultural, na ideia de que não há como se distanciar de algo que depende de você para poder existir.

Portanto, a ideia de poder assumir uma posição totalmente neutra, objetiva e distante acerca de questões humanas não é razoável, já que necessariamente, ao analisar objetos culturais, estamos envolvidos em suas disputas internas, nossas tendências pessoais entram em campo, e esses objetos, como dependem, da mesma mente que os analisa, a sua existência e sustentação, não seriam passíveis do ato de distanciamento, como ocorrem com os objetos das ciências da natureza, que tem uma existência própria, independente da mente humana, pois não são, essencialmente, objetos culturais, e portanto podem ser vistos com um certo distanciamento.

A analogia com mapas esclarece melhor esse ponto - um mapa físico, que represente traços de rios, florestas, desertos e montanhas, ou seja, que represente uma expressão da natureza é bem diferente de um mapa político, que represente fronteiras políticas de Estados Nações, fronteiras políticas essas que muitas vezes não se fundamentam em obstáculos naturais, mas em convenções diplomáticas. No mapa político, seus traços muitas vezes não contam com nenhum obstáculo geológico visível, sendo impossível sua precisão em determinadas regiões desérticas ou montanhosas por exemplo. Essas fronteiras políticas fazem uma analogia com o objeto das ciências humanas: para existir precisa de um suporte físico, que é uma pessoa viva 
que o pensa, que o sustenta mentalmente e que seja capaz de compreender os consensos políticos e jogos de poder humanos que fazem daquela fronteira algo inteligível.

Analisando o distanciamento científico pôr esse viés, fica claro perceber que o ato de analisar com distancia algo que é sustentado pela mesmo instrumento que sustenta a análise, ou seja a mente, é algo questionável. Em outras palavras, como se utilizar a mente para se distanciar de algo que precisa da mente para existir? Dito de outra maneira: se o ente cultural só existe sustentado pela mente humana, como pode essa mesma mente, ao mesmo tempo, sustentar e criar o ente e ainda assim analisá-lo com distância?

A minha tese é de que a mente não se distancia de "objetos" que necessitam dela para existir. Esse é um fator de distinção entre as ciências humanas e as ciências naturais - enquanto nas ciências naturais os objetos não necessitam de uma mente humana para existir, as estrelas, os animais, as plantas, por exemplo, mesmo sofrendo a intervenção dos sentidos e dos significados da análise, mesmo sua realidade passando por "filtros" biológicos, culturais e tecnológicos, esses “objetos” tem uma realidade própria fora do âmbito cultural humano. Nesse sentido, os objetos das humanidades, como entes culturais, necessariamente precisam de seres humanos pensantes para existir, objetos esses que passam a ser ressignificados e analisados pela mesma mente que o sustenta.

Por esse viés, a visão imparcial ou muitas vezes a busca por leis gerais das ações humanas, das sociedades, ou seja, as estruturas e leis das ciências sociais, perdem seu fundamentos na medida que elas carregam o fetiche de serem elaboradas segundo os instrumentos teóricos de análise que distanciam o pesquisador ou o teórico de seu objeto, no fetiche de uma visão "dos bastidores" ou "de cima da montanha", visão essa que "possibilita" a arguição de leis ou estruturas do comportamento humano, ou melhor, das coletividades, com a mesma precisão de distanciamento conferido aos objetos das ciências na natureza.

É com essa preocupação que Durkheim teoriza o "fato social" como algo fora do universo mental do indivíduo, como algo maior que ele, e que é o próprio objeto da Sociologia, na tentativa de estabelecer um objeto semelhante aos objetos das ciências naturais. No entanto, em sua teoria se omite o fato de que esse mesmo "fato social" é uma abstração mental individual que necessita de alguém pensando nele para ele "existir". Ou seja, o "fato social", por mais que carregue a ideia de algo que escape da individualidade ou subjetividade pessoal, é ao mesmo tempo, dependente de uma subjetividade individual vivente, a do pesquisador, por exemplo, para existir. Esse paradoxo fundamental, se fosse levado em consideração, inevitavelmente 
levaria a Sociologia a ter uma epistemologia distinta, o que provavelmente também negaria a possibilidade de sua pretensão do distanciamento.

Esse pequeno exemplo demonstra uma distância epistemológica significativa entre os dois projetos de Sociologia que entraram em debate, logo quando a disciplina surgia nos anos finais do século XIX. Enquanto que em Gabriel Tarde a cerne da interpretação sociológica estaria ligado ao indivíduo, ou melhor, na "mônada" (Tarde tomou de empréstimo esse conceito de Leibniz), a contar também com uma concepção, por ele insuperável, devido a sua vida como jurista, de que o conhecimento das relações sociais ou da sociedade provém de meditações solitárias, assim como na Filosofia, o projeto de Emile Durkheim lançou suas bases na negação do indivíduo, ou na superação da esfera subjetiva e psicológica deste, para estabelecer o que viria a ser o objeto da Sociologia: o "fato social”, para além de qualquer subjetividade e vivência pessoal é uma realidade que coage ao indivíduo, mesmo que este não a perceba (ao contrário do teórico, que acredita assim o fazer).

Essa qualidade intrínseca da investigação social defendida por Tarde, de que o conhecimento social advém, não de uma formação profissional padronizada, mas sim de atributos intelectuais singulares do pesquisador, foi muito bem explorada por Luís de Gusmão em Ofetichismo do conceito: limites do conhecimento teórico na investigação social, livro esse que forneceu parte da inspiração presente na concepção desse artigo. Gusmão aponta que o valor cognitivo de um trabalho de investigação social está mais atrelado ao próprio talento do pesquisador, do que a uma iniciação científica prévia, que o faria portador de uma visão teórica inalcançável ao senso comum.

Portanto, como assinala Gusmão, no âmbito da psicologia humana, os clássicos da literatura de todas as épocas e civilizações estão muito mais próximos em expor a natureza das paixões humanas do que os cientistas de formação acadêmica em Psicologia, que, supostamente, são iniciados em visões teóricas que não encontramos no senso comum.

A crítica ao distanciamento é, ao mesmo tempo, uma crítica à ideia de que historiadores assim como cientistas sociais poderiam dispor de teorias que pudessem percorrer grandes áreas rapidamente, sem ter de se ater, necessariamente, ao trabalho vagaroso da pesquisa empírica. Como bem aborda Gusmão, tal teoria nunca foi encontrada, por mais que se insista em sua busca, e por mais que se defenda um modelo que, em grande medida, já entrou em colapso, como foi discutido, em relação às modas científicas.

\section{Filstistorias}


Diferentemente da análise de Gusmão, esse artigo propôs-se a discutir que a prática do “distanciamento científico" está ligada a uma crença de que, na pesquisa social, objetos culturais podem ser vistos como objetos naturais. Portanto, esse artigo acaba por trazer à tona uma antiga quimera, que trata das diferenças entre ciências da natureza e ciências do espírito. Para a escola metódica essa questão era bem resolvida: a História é a ciência do singular, jamais será uma ciência objetiva, tendo em mente a objetividade existente nas ciências da natureza. Portanto, ela, a História, tem uma metodologia de pesquisa própria, ligada à empiria, à crítica das fontes e à erudição (e também ao conhecimento de disciplinas auxiliares). Assim também, como narrativa, a História ao mesmo tempo que é ciência, também é arte, porque sua forma final é literária, que não exclui a análise, a compreensão e a discussão meta-narrativa (teórica).

Podemos afirmar, por conseguinte, que o distanciamento de um objeto cultural, na tentativa de analisá-lo como um objeto nas ciências da natureza, é mais um fetiche, de busca de legitimidade científica, segunda a legitimidade conquistada por essas ciências e seus feitos, do que uma prática real de aproximação científica. Assim, na impossibilidade de distanciar-se de um ente cultural, a criação de leis que possam reger o comportamento humano e o estabelecimento de estruturas e esquemas de análise macrossociais totais que moldam os acontecimentos, já não mais se sustentam.

O desuso desses esquemas globais de interpretação no surgimento e queda de modas científicas durante boa parte do séc. XX é o sintoma apenas de algo maior que este artigo tentou esboçar, na denúncia de um erro fundamental, por banal: a suposição de possibilidade de se distanciar de entes culturais criou um fetiche de distanciamento que poderia produzir leis do comportamento coletivo que estariam acima dos lutas políticas e do envolvimento do pesquisador com as disputas e intrigas da realidade social, seja de sua época, seja do passado, na crença também de que esse distanciamento poderia evidenciar e analisar novos entes, objetos esses que mesmo sendo produtos da mente humana e sustentados por ela, carregariam a ideia de serem não humanos, ou seja, carregariam o fetiche de serem naturais, à espera de alguma mente brilhante munida de uma teoria inovadora, capaz de distingui-lo entre os afazeres do diaa-dia a que o senso comum, por estar tão envolvido, não seria capaz de percebê-lo. 


\section{Referências Bibliográficas}

CHARTIER, Roger. A História Cultural: entre práticas e representações, Lisboa: Difel, 1990.

DELACROIX, Christian; DOSSE, François; GARCIA, Patrick (Dir.). As correntes históricas na França. Rio de janeiro: Ed. FGV, 2012.

DOSSE, François. A História. Bauru, São Paulo, EDUSC, 2003.

DURKHEIM, É. As Regras do Método Sociológico. São Paulo, Martins Fontes, 2007.

GADAMER Hans-Georg. Verdade e Método. Petrópolis, Rio de Janeiro: Vozes, 2008.

GUSMÃO, Luís de. O fetichismo do conceito. Limites do conhecimento teórico na investigação social. Rio de Janeiro: Top Books, 2012.

KOSELLECK, Reinhart. Futuro passado. Contribuição à semântica dos tempos históricos. Rio de Janeiro: Contraponto/PUC-Rio, 2006.

REVEL, Jacques. Cultura, culturas: uma perspectiva historiográfica. In: Jacques Revel. Proposições. Ensaios de história historiografia. Rio de Janeiro: Ed. UERJ, 2009.

História e historiografia. Curitiba: Ed. UFPR, 2010.

RICCEUR, Paul. A memória, a história, o esquecimento. Tradução de Alain François et al. Campinas, SP: Ed. Unicamp, 2007. Publicando originalmente em 2000.

SCHRAMM, J.F. Por uma teoria da História pela História. Monções, UFMS/CPCX, v.1, n.1, p. 159-173, 2014,

SILVA B.H. Encontros entre História e Sociologia: primeiros embates metodológicos na França. História e Cultura, Franca, v.3, n.3 (Especial), p. 7-27, dez. 2014.

TARDE, Gabriel. Monadologia e Sociologia. São Paulo: Cosac Naify, 2007. 